\title{
Understanding the Lived Experience of Children With Type I Diabetes in Kenya: Daily Routines and Adaptation Over Time
}

\author{
Tom Palmer' $\odot$, Cynthia Waliaula', Geordan Shannon', Francesco Salustri', \\ Gulraj Grewal $^{2}$, Winnie Chelagat ${ }^{2}$, Hannah M. Jennings ${ }^{3}$, and Jolene Skordis'
}

\begin{abstract}
Focusing only on biomedical targets neglects the important role that psychosocial factors play in effective diabetes selfmanagement. This study aims to understand the lived experiences of children with Type I Diabetes (TIDM) in Kenya. Children $(n=15)$ participated in focus group discussions and photo diary data collection. Focus group discussions and semi-structured interviews were also conducted with caregivers $(n=14)$. We describe an adaptation to diabetes over time, identifying four overarching themes: knowledge and awareness, economic exclusion, the importance of social support, and striving for normality. Photo diaries are then categorized to explore daily realities of diabetes management. Children with TIDM in Kenya face varied barriers to care but can lead a "normal" and fulfilling life, provided adequate support is in place. To improve the lives of children with diabetes in this context and others like it, stakeholders must take note of children's experiences and recognize their multidimensional needs.
\end{abstract}

\section{Keywords}

children, adolescents, youth, diabetes, stigma, qualitative health research

\section{Background}

Each year an estimated 130,000 children and adolescents are newly diagnosed with Type 1 Diabetes (T1DM) globally (Saeedi et al., 2019). With appropriate management, children and adolescents with T1DM can lead healthy and fulfilling lives. However, a diabetes diagnosis is just the first hurdle in ensuring appropriate care for those who need it. Even with adequate healthcare in place, T1DM is a challenging disease to manage. Maintaining glycemic control requires a variety of self-care strategies including exercise, meal plans, frequent blood glucose monitoring, and the storage, preparation, and administration of insulin. For children, meeting targets for glycemic control is also associated with high levels of parental support and involvement in disease management (Dashiff et al., 2008; Wysocki et al., 2009). Adolescents with T1DM in particular often have poor glycemic control, as they transition from childhood toward independence. A study in Kenya found that, on average, only $4 \%$ of adolescents enrolled in care for T1DM had reasonable glycemic control, defined by measured $\mathrm{HbAlc}$ of $8 \%$ or less (Ngwiri et al., 2015).
Adequate glycemic control is critical to prevent subsequent complications such as retinopathy, nephropathy, and neuropathy (Diabetes Control and Complications Trial Research Group, 1993). However, focusing only on biomedical targets neglects the important role that psychosocial factors play in effective self-management. Such factors are particularly challenging for children and adolescents. Various forms of stigma in relation to diabetes have been reported in the literature globally, including discrimination in marriage, schooling, and employment opportunities (e.g., Abdoli et al., 2013; Aono et al., 2000; Jaacks et al., 2015) and experience of stigma may be associated with poor glycemic control (Capistrant

\footnotetext{
'Institute for Global Health, University College London, London, UK

${ }^{2}$ Global Health Disrupted, Nairobi, Kenya

${ }^{3}$ Department of Health Sciences, University of York, York, UK

${ }^{4}$ Diabetic Association of Bangladesh, Dhaka, Bangladesh

\section{Corresponding Author:}

Tom Palmer, Institute for Global Health, University College London, 30 Guilford Street, London WCIN IEH, UK.

Email: t.palmer@ucl.ac.uk
} 
et al., 2019). Quantitative estimates of the prevalence of stigma experienced by children with diabetes have focused on high-income countries, but have found widespread prevalence reported by both children and caregivers (Brazeau et al., 2018; Gredig \& BartelsenRaemy, 2017; Liu et al., 2017).

A number of qualitative studies have described the lived experience of a child with T1DM in high income settings (see e.g., Huus, 2007; Marshall et al., 2009; Miller, 1999; Rankin et al., 2018; Sparapani et al., 2015). However, the qualitative literature in low- and middleincome countries (LMICs) is more limited. A study in Tajikistan describes the perceptions and experiences of living with T1DM in Tajikistan, finding that some families perceived "emotional stress" and a spiritual "evil eye" as potential causes of diabetes (Haugvik et al., 2017). A study in Zambia found that children with T1DM often experienced stigma, and that families promoting the use of traditional medicine, rather than insulin, was a significant risk for children (Hapunda et al., 2015). These studies highlight the need for clear guidance and information following a T1DM diagnosis. In Bolivia, Souris et al. (2019) found that living with T1DM is simply "normal life" for many children and adolescents, but individuals varied in how they achieve this normalcy. While some adapted their lives to accommodate diabetes management, others resisted changes such as diet adaptation, perhaps as a coping mechanism prompted by fears of stigma.

Beyond the challenges faced by children and adolescents in high income countries, many children in LMICs also face substantial structural barriers to care, including financial burden. A study of 15 LMICs, including 7 in sub-Saharan Africa, found that annual care costs for children with T1DM ranged from $\$ 255$ to $\$ 1,185$ with a median of $\$ 553$ (Ogle et al., 2016). These costs are significantly beyond the means of many families in these settings. A qualitative study in Ghana (Kratzer, 2012) identifies five key structural barriers to effective disease management for families of children with T1DM. In addition to the financial burden, these include misdiagnosis or lack of appropriate care at primary care facilities, discrimination and lack of care at schools, lack of formal support and advocacy, and limited access to appropriate information. The combined experience of stigma, discrimination, and structural barriers often amount to insurmountable barriers to effective care for children with T1DM in LMICs.

These complex issues can be better understood through an approach focusing on children's lived experiences. One approach to this is through the use of photo diaries. Participatory research methods, such as photo diaries, are an accessible and interactive way of enabling young participants to capture and reflect on their lived experiences and their environments (Allen, 2009; Kleine et al.,
2016; Mizen, 2005; Young \& Barrett, 2001). Whilst some studies in the US have used photovoice methods to provide insight into the perspective of children with T1DM (Walker et al., 2016; Yi-Frazier et al., 2015), photo diaries have not previously been used in T1DM research amongst children in LMICs to our knowledge. Therefore, in this study, we aim to expand our current understanding of the lived experiences of children living with T1DM by using a combination of focus group discussions, interviews, and photo diaries with a cohort of children, carers and health workers in Kenya.

\section{Methods}

\section{Study Setting}

Kenya is a lower-middle income country in East Africa. Kenya's healthcare system, following a process of devolution, is delivered by 47 county governments. Health services are organized into 6 tiers of increasing comprehensiveness from community health facilities to tertiary care. Levels 1-3 refer to sub-county community health centers, dispensaries, and health centers that focus on health promotion, basic outpatient services, emergency inpatient care and referral to higher levels. Level 4 facilities are sub-county referral hospitals, while level 5 facilities are county referral hospitals that offer comprehensive inpatient care, specialized outpatient clinics, and management of cases referred from lower facilities. Finally, level 6 hospitals are national referral hospitals and large private hospitals that offer highly specialized care, medical training, and research. Facilities within levels 4-6 contain specialized diabetes clinics where patients are able to access services on specific days. Education, preventive services, and sometimes medications are offered on all other levels as per the Kenya Health Policy 2014-2030 (Ministry of Health, 2014). This system applies to both adults and children with diabetes.

Although International Diabetes Foundation estimates suggest that in Kenya there are approximately 1,694 children with T1DM (Saeedi et al., 2019), this figure may be an under-estimate due to the structural and social barriers to diagnosis and care outlined briefly above.

\section{Study Design}

The Changing Diabetes in Children (CDiC) program is a private-public partnership initiated by Novo Nordisk that aims to improve access to diabetes care for children with T1DM in LMICs. Participants were recruited to this study in the context of an evaluation of CDIC in Kenya. The main results of the evaluation are reported in a separate article (Palmer et al., 2021). The evaluation design included facilities implementing the $\mathrm{CDiC}$ program, in 
addition to a purposively selected "control" facility, used to inform conclusions regarding program effectiveness. Data collected through the $\mathrm{CDiC}$ evaluation are analyzed in the present article to give a broader overview of the lived experience of children with diabetes in Kenya.

Data collection took place in Kenya between March and April 2019. Children aged between 5 and 17 and their caregivers were recruited into the study. Healthcare workers were also recruited in the wider study, though their responses are not the primary focus of this article and are reported elsewhere (Palmer et al., 2021). However, some insights from healthcare workers were used to provide additional context to our analysis. A total of 15 children participated in the study ( 7 boys and 8 girls). Age was reported by 11 of the 15 children, with a mean age of 12.7 (standard deviation 3.85). Approximate age of participating children is shown in Table 1 where possible. Participants were selected in a purposive convenience sample, with local health services assisting in selection. All participating children were enrolled in treatment for T1DM. Children and caregivers were recruited for focus group discussion through diabetes clinics at four facilities: three CDiC facilities and one "control" facility. All four were urban facilities. However, aside from one facility in Nairobi, each serves a wide catchment area and participants may have been from urban, semi-urban or rural areas, often traveling long distances to receive care.

Sample size was based primarily on pragmatic considerations such as participant availability during the data collection period. This followed an initial estimate of anticipated sample size prior to commencing research. That said, using constant comparative analysis of the data being collected, we determined that thematic saturation, as defined as the point at which additional qualitative data provides no further information and codes are repeated (Kerr et al., 2010), had been reached in later focus group discussions.

Our study adopted an approach based on reflexive thematic analysis to identify, describe, and analyze patterns in the data (Braun \& Clarke, 2006). This methodology does not require a specific theoretical framework and offers a flexible approach to data collection. Data analysis was inductive, such that analysis was not guided by pre-existing theories. As the objective of our study is to understand the lived experiences of children living with

Table I. Approximate Age Groups of Participating Children.

\begin{tabular}{lcc}
\hline \multicolumn{1}{c}{ Age group } & $\begin{array}{c}\text { Number of boys } \\
\text { participating }\end{array}$ & $\begin{array}{l}\text { Number of girls } \\
\text { participating }\end{array}$ \\
\hline $5-8$ years old & 1 & 1 \\
$9-13$ years old & 1 & 1 \\
14-17 years old & 4 & 4 \\
Unknown & 1 & 2 \\
\hline
\end{tabular}

T1DM, we chose a methodology that would ensure freedom for participants to express complex experiences in their own words. Therefore, we adopted a realist approach, focusing largely on semantic features of the data.

\section{Data Collection}

Children and caregivers each participated in focus group discussions about their experiences of diabetes care. Children participated in a total of 4 focus group discussions, with between 2 and 5 participants in each discussion. Caregivers participated in 3 focus group discussions, with between 3 and 5 participants in each discussion. Each focus group discussion lasted approximately 30 minutes. A further 2 caregivers participated in individual semistructured interviews. Qualitative semi-structured interviews were also conducted with healthcare workers at each facility. Separate discussion guides for children, caregivers, and healthcare workers were developed prior to beginning data collection. Qualitative data were collected in an iterative manner, allowing modification of topic guides when important issues emerged.

Following the focus group discussions, we also provided families with mobile phones to enable photo diary data collection. Caregivers and children were encouraged to capture their healthcare experiences and challenges in relation to diabetes. Complementing focus group discussions with this method can overcome some of the limitations in using conventional research methods with children. For example, low confidence, ability to concentrate, and weaker language skills. It may also allow the researcher to gain a deeper understanding of the children's lived experience which would otherwise require a large amount of time spent with them. Children will feel empowered as active voices in the research, as they will be in control of which photos they choose to represent their experience, and tend to enjoy taking photos (see e.g., Punch, 2002).

Each child in the group, and their parents if appropriate, were shown how to use the phones and briefed on the types of photos they may take - anything that relates to their diabetes, support, and treatment. The phones were only available to take photos on (i.e., they had no sim card so did not function to make calls) and it was made clear they were on loan for the purpose of the research. Each participant was asked to take at least 3 photos and return the phone to the facility the following day. Although children returned their phones with captured photos to the facility, photo diary data was not discussed with the children in a followup session due to logistical constraints.

\section{Data Analysis}

Field interviews were conducted by a trained interviewer, paired with an experienced translator and note-taker. After 
the participant gave consent, the interviews and focus group discussions were audio recorded and detailed interview notes taken. Focus group discussions and interviews with caregivers and children were conducted in Swahili, while interviews with healthcare workers were conducted in English. A team of transcribers transcribed verbatim all interviews in their entirety directly into English. To check the quality of the translation, a sample of interview segments were also translated a second time.

All transcripts were analyzed in-line with the principles of Braun and Clarke's (2006) six-phase framework for thematic analysis, including familiarization with data, initial generation of codes, searching for themes, reviewing themes, defining themes, and writing the final report. Before coding the transcripts, two researchers read through the transcripts multiple times to gain familiarity with the data and to identify initial coding ideas within the text. Next, a line-by-line thematic analysis of each transcript in its entirety to label segments of text was conducted by both researchers independently. The two researchers then discussed their initial codes, which were categorized into preliminary groups, then further restructured into themes and subthemes in an iterative process. Data were analyzed repeatedly throughout this process to ensure interpretive depth. Finally, themes were refined and finalized, and quotes selected from transcripts to accompany each theme. A separate content analysis of photo diaries was conducted to determine the primary category of representation in each photograph. All data were analyzed manually.

We took several steps to ensure the validity of our data, in line with the recommendations of Morse (2015). To improve the credibility of our findings, we spent time engaging with multiple readings of all collected data before beginning the analysis. A clear analysis process was documented by the researchers to ensure an audit trail. To avoid personal biases, both researchers met to review and finalize code choice following the initial coding stage. Additionally, one of the researchers is Kenyan, which helped to ensure interpretation of findings was culturally and contextually appropriate. Finally, researchers not directly involved in the analysis of transcripts also provided insight on analysis results in a process of peer review.

\section{Ethics}

All participating children were recruited through diabetes clinics and gave assent to participate, including assenting to the use of audio recordings and photo diary methods. Written consent was also obtained from their caregivers, and from healthcare workers.

Ethical approval was granted by the University College London Research Ethics Committee (14657/001). Local ethical approval was granted by the Amref Ethics and
Scientific Review Committee in Kenya. Neither committee placed any conditions or restrictions on the age of participants. The program funder (i.e., Novo Nordisk) was not involved in the design or implementation of the study, did not have access to any primary data collected and was only presented with study results after the study had finished. UCL partnered with Global Health Disrupted, a non-government organization, for local expertise and research support.

\section{Results}

The results of the analysis are presented in two sections. In the first section, children's adaptation to diabetes over time is discussed. The thematic analysis identified four overarching themes that reflect this adaptation: knowledge and awareness, economic exclusion, the importance of social support, and striving for normality. In the second section, the photo diary results are categorized to explore the daily realities of diabetes management for a child in Kenya, drawing upon results from the interviews where relevant.

\section{Adapting Over Time}

Theme I: Knowledge and Awareness. Prior to diagnosis and in the early stages of their illness, children's experience of diabetes is defined by awareness, or lack thereof. This extends to their caregivers, their immediate family and the community at large. Where awareness of diabetes does exist, this is typically of Type 2 diabetes. Diabetes is therefore often seen as a "lifestyle disease," and not something which can affect children. As a result, children are typically diagnosed late in relation to symptom onset, often after admission to hospital with severe complications such as diabetic ketoacidosis and having experienced symptoms such as tiredness and excessive urination for a long time. Given the genetic nature of TD1M, the period prior to diagnosis can be shortened where siblings are both affected, as families are already familiar with diabetes symptoms.

"I used to read my sister's books because she's also diabetic and I would look at the signs and symptoms and I realized that I had the same signs and symptoms"

Girl, 14-17 years old

While the child in this instance reported a delay in revealing symptoms due to fear, we see that education about the illness could lead to earlier diagnosis, better management, and avoidance of long-term complications.

Healthcare workers played a crucial role in providing information for children, their caregivers, and their social circles. However, a lack of prior experience in dealing with 
T1DM in children often delayed diagnosis. This was due to a low index of suspicion causing them to initially investigate for more common illnesses such as gastrointestinal infections and malaria. Additionally, some healthcare workers contributed to misconceptions and misinformation with suggestions that the illness could be cured over time.

"The doctor told me that this was just a passing disease and I could get healed. It's only after two months had passed then when I realized that this was something I was going to live with. By then I was used to it, so I just accepted."

Boy, 14-17 years old

Over time however, most children and their caregivers appear to gain adequate knowledge and understanding of the long-term nature of their condition and its management, pointing to the importance of accurate and accessible information. They were able to assist with their own management from a young age and even able to identify the symptoms associated with impending complications. For example, one caregiver reported that their child refused to be injected with insulin, although their doctor wanted to do so, as she could tell that her sugars were low.

\begin{abstract}
"But the doctor said he had just tested sugars and they'll have to wait for another 6 hours before they do so again. She insisted and asked the doctor not to inject her with insulin first. The doctor was puzzled and was like 'Eva we just tested your sugars and it was in the 20s range!' but Eva refused and asked me to remove her machine and test her sugars. When I did, she was at 2!".

Caregiver of child with T1DM
\end{abstract}

The girls' caregiver was convinced that the consequences of injecting insulin on that occasion would have been severe, had their daughter not insisted. This highlights the vital importance of accurate and accessible information and education. In some cases, doctors successfully educated teachers to provide care for children at school:

"The doctor at Kenyatta asked me to choose two teachers to be trained and that's what we did and now they are able to administer the insulin"

Caregiver of child with T1DM

However, such positive experiences of teachers participating in diabetes care were far from universal (see Theme 3 below).

\section{Theme 2: Economic Exclusion}

T1DM is an expensive illness to manage, particularly in low-income households where resources are limited, and healthcare is often prohibitively expensive. The financial burden imposed by the illness was pervasive throughout the participants' lives and therefore a major barrier to effective disease management. Financial costs were wide-ranging, including those associated with buying insulin, syringes, and other medical supplies, in addition to other costs such as food and transportation. Many children and parents reportedly traveled long distances from rural locations to attend clinics, in some cases, traveling up to $300 \mathrm{~km}$. This could cost up to around 500 KES (approximately \$5 USD) each way per person. As a result of these distances and costs, children were often unable to attend the clinic as expected on their clinic day. Although in intervention facilities the provision of insulin was free, parents frequently reported lacking transportation money to attend the facility to collect it. While the CDiC facilities greatly subsidize the cost of treatment, they sometimes appeared to lack equipment resulting in caregivers funding their children's treatment:

\footnotetext{
"Some of the things that I have to buy are syringes and needles. Sometimes when we come here, we're told the strips have not been delivered yet. Also, the transport to the hospital is expensive. We usually spend around 300KES every time we come to the clinic. I usually pay for these things with cash. It is difficult but we have to do it for our children because they don't have anybody else."

\section{Caregiver of child with T1DM}

In non-CDiC facilities, the issue is compounded both by the cost of insulin and the rationing of insulin. Caregivers reported that they were only allowed to take one vial of insulin each visit, requiring more frequent visits and significantly increasing transport costs. Children were also acutely aware of the costs that treatment imposed on their caregivers, which placed a psychological burden on them:

"The challenge that I face is that I know sometimes my mom lacks transport to come pick the insulin from hospital."

Girl, 5-8 years old

They sometimes even made decisions detrimental to their health in a bid to protect their caregivers:

"For me, the challenge has been getting needles. Sometimes I reuse them too much to the point where I get wounds. Sometimes I feel like I am bothering my parents asking for them because they are expensive. So, I prefer to just keep it to myself and use what I have."

Girl, 14-17 years old

Theme 3: Importance of Social Support. The level of social support extended to children and their parents by the 
community resulted in an environment that either fostered acceptance or caused resentment and social exclusion. Children with diabetes faced multiple forms of social exclusion, stigma, and discrimination. Although stigma amongst parents could be overcome by counseling at health facilities, reducing stigma in the community was perceived as more difficult. Stigma was frequently reported by parents and healthcare workers, though the prevalence and nature of stigma varied by region. For example, beliefs in witchcraft were reportedly less common in Nairobi. Some parents were worried about letting the wider family and community know the truth about their child's diagnosis. These parents believed that if people found out they would try to harm or kill the child:

A: To be honest, our neighbors and relatives have no idea about his condition. We wouldn't want anyone to wish them death. You never know what people's intentions are with your children. Can you imagine if they find out what his triggers are? Or what can cause him harm...We'd rather deal with it as a family."

Caregiver of child with T1DM

B: "Yes! They can even go to a witchdoctor to bring harm to your child. I also do not want my child to be treated differently. So, it's just my family that knows and supports him. Not even my extended family."

Caregiver of child with T1DM

In the worst cases of stigma, there were reports that the children were considered "bewitched," "doomed," or "cursed." One child reported being told to "go and die." Stigma was also suggested as a reason for poor compliance to treatment with insulin.

As a result of this stigma, caregivers may not tell their child's school that their child is diabetic. Teachers often have a poor understanding of the needs of diabetic children. Children and caregivers both reported turning to teachers for support but finding that they were unwilling or unable to give it:

"The teachers do not get it too. It's just hard. You'd rather just do everything secretly."

Boy, 14-17 years old

"I have not told anyone because I do not want my child to be treated differently. I once tried talking to her teachers but it seems they do not want to understand! Teachers in schools should also be educated about this condition. I thought they are the ones who should know!"

Caregiver of child with T1DM

"For me, I've realized the teachers who do not care about these children or they do not have the heart to help the children. If the child is seemingly weak, they usually just look at the child until that point where she collapsed and then they start seeking for help".

Caregiver of child with T1DM

In some cases, children are rejected from schools altogether because the schools feel unable to care for them or because they do not want a child with diabetes. As schools refusing to admit diabetic children has become so common, we heard that in 2019 an Inter-Agency Coordinating Committee has stepped in to facilitate communication between the Ministry of Health and the Ministry of Education, in order to resolve the issue. Where schools are willing to accept children, they are often unable to meet the needs of the children, especially with regard to diet. Both teachers and the children's peers often lack knowledge of diabetes. This not only heightens stigmatization but also has a negative effect on the children's willingness and ability to manage their condition:

"When I would go to school I was a bit shy eating in front of the students because it would seem like I'm a glutton and I would end up starving myself. At this point I used to feel a lot of dizziness and my sight was really affected..."

Boy, 14-17 years old

However, many participants, had a considerable level of support from their immediate families in a variety of ways, including accommodating dietary changes, administering insulin injections, and moral support and encouragement.

\section{Theme 4: Striving for Normality}

Both parents and children were aware of the additional strain that living with T1DM placed on their lives and appeared to strive for some sense of "normality." Parents reported that both they and their children were aware that T1DM made their lives different from other children. An example of this is the multiple admissions that children suffered both prior to and in the period following diagnosis. For a few of the older children, this led to numerous school interruptions and poor academic performance:

"However, when I got to class 6, I realized that it was really affecting me because my grades were going down. I used to be sent home a lot because of being sick."

Boy, 14-17 years old

Moreover, as T1DM is largely diagnosed in childhood, parents initially bear the burden of dealing with their young children and helping them understand and manage 
their condition. In this study, parents expressed distress and had some difficulty in processing their children's lifelong condition given the early age of diagnosis. Administering medication to young children also caused parents a lot of anguish:

"It's stressful because it's hard to understand how a child can have diabetes. And then now you have to inject a child and every time you're doing it and they're crying and you're wondering why do I have to go through this."

Caregiver of child with T1DM

"My child still does not understand why he's being injected and the other kids are not being injected. Every time we run out of insulin he begs us not to buy more because he knows more insulin means more injections. Sometimes it's very difficult."

Caregiver of child with T1DM

Accepting the substantial changes necessary to adapt to T1DM also brought many challenges to children's home lives:

"Sometimes she gets really angry and she gets really agitated when she's interacting with her siblings, especially the fact that there are some foods that she's not allowed to eat. I really struggle with her accepting her diet to a point where there are those times where she says she does not want to eat and she will refuse to eat completely."

Caregiver of child with T1DM

As children get older and become adolescents, their desire to appear "normal" becomes stronger. Adolescent diabetics often do not want to attend clinic days or to moderate their diet. Instead, they often end up eating the same diet as their peers. Those peers may associate the use of syringes with illegal drug use, which can lead to a reluctance to inject insulin publicly. As one parent explained:

“Another challenge I'm experiencing now is that she's becoming an adolescent... they are moody when you talk to them, they get mad and it's always as if you're not doing the right thing. You're never sure when they're injecting themselves or whether they are actually injecting themselves and it's just very difficult to control them. It's much easier when they're smaller because you can help and they cooperate"

\section{Caregiver of child with T1DM}

Children responded differently when talking about the level of acceptance and openness regarding their diabetes at school. Some children were very comfortable with being diabetic, and with injecting insulin in class. Others felt the need for secrecy, as they feared exposure would lead to harsh treatment from their peers, such as vandalizing their locker or desk to attempt to steal their glucometer. They reported that peers did not understand the importance of their glucometer or what they are used for.

"I'm very comfortable with being diabetic and everyone knows that I'm diabetic. I can inject myself in class or in the dispensary"

\section{Girl, 14-17 years old}

"I have to fend for myself and I have to also try and keep up with my classes and sometimes I do need to go outside class to go and take my injection or take a meal so it's difficult. I also try and keep my condition secret because if I exposed things like the glucometer someone might vandalize my locker."

Boy, 14-17 years old

Whereas some children were highly integrated, for example, participating in the school rugby team, others said that they avoid extra-curricular activities as a result of their diabetes.

"it's true I'm doing really well in sports I am in the rugby team so I know we can do anything that you want to do"

\section{Caregiver of child with T1DM}

"I also stay away from participating in co-curriculum activities which would require us to go for trips outside school because I have no way to store my insulin."

Girl, 14-17 years old

Managing day-to-day. While the themes outlined above covered how children had adapted over time with a focus on key milestones, challenges, and events, the photo diary results were generally focused on the daily realities of living with diabetes. Photos were almost all categorized under the themes of food, insulin use, or socializing. Uniting all of these categories was a desire for children to demonstrate their independence. In the below sections, the main photo diary results are summarized, supplemented by data from interviews where relevant.

\section{Photo Diary Category I: Food Management}

Food was a key focus of the photos taken by children (some examples are shown in Figure 1). The importance of balanced nutrition for diabetes management, in addition to the use of snacks for controlling blood sugar, was clearly evident to children from a young age. Children were not asked specifically to document their diet, but 


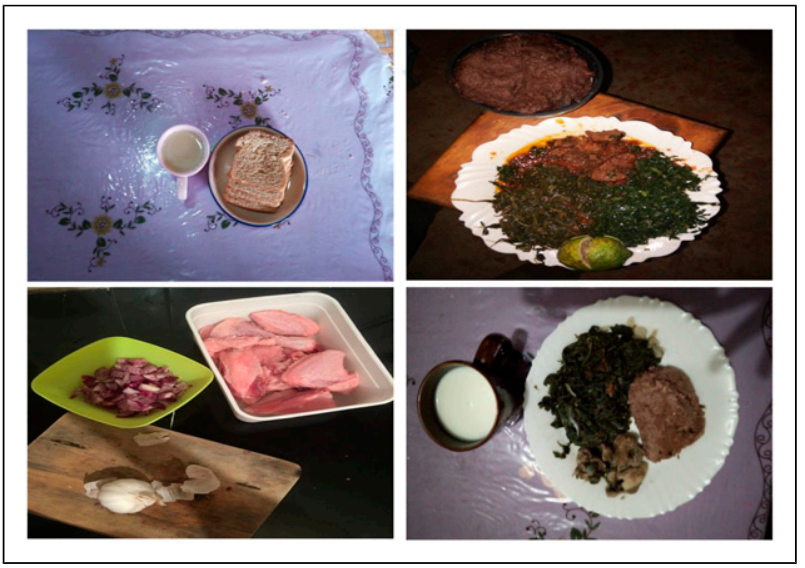

Figure I. Photographs of meals and snacks.

almost every child participating did so, reflecting that this is a key concern in their day-to-day life. Children were proud of their ability to manage their diet independently and showed a high level of nutritional awareness. For example, knowing that brown rice is more nutritious than white rice, or reporting that they based meals on a guideline ratio of $1 / 4$ protein, $1 / 4$ carb, and $1 / 2$ vegetable per plate. They were also aware of the impact on their blood sugar levels if they were forced to skip meals or snacks, such as in school.

Despite high levels of nutritional awareness, we heard that school presented a particular challenge to maintaining an appropriate diet. Teachers were often unwilling to accommodate dietary adjustments, despite visits from parents to explain their child's needs. One caregiver reported that a teacher ignored their child's request for food, insisting that they stay until the lesson finished, resulting in low blood sugar and collapse. Caregivers also reported that this special diet was significantly more expensive than the diet for a non-diabetic child. One caregiver (of a child enrolled at a non-CDiC facility) said that they are sometimes forced to choose between providing a balanced diet and providing insulin, as the combined costs are unaffordable.

Of note, one caregiver also highlighted the difficulty in adhering to a proper diet where the child had a comorbidity: "The one big challenge that we are facing now is that the
autism diet and the diabetic diet are clashing. Autism en-
courages traditional foods and that is things like sweet po-
tatoes and arrowroots. But you see sweet potatoes would
bring his sugars up."

Caregiver of child with T1DM

\section{Photo Diary Category 2: Insulin Handling}

Another aspect of disease management where children were proud of demonstrating their independence was

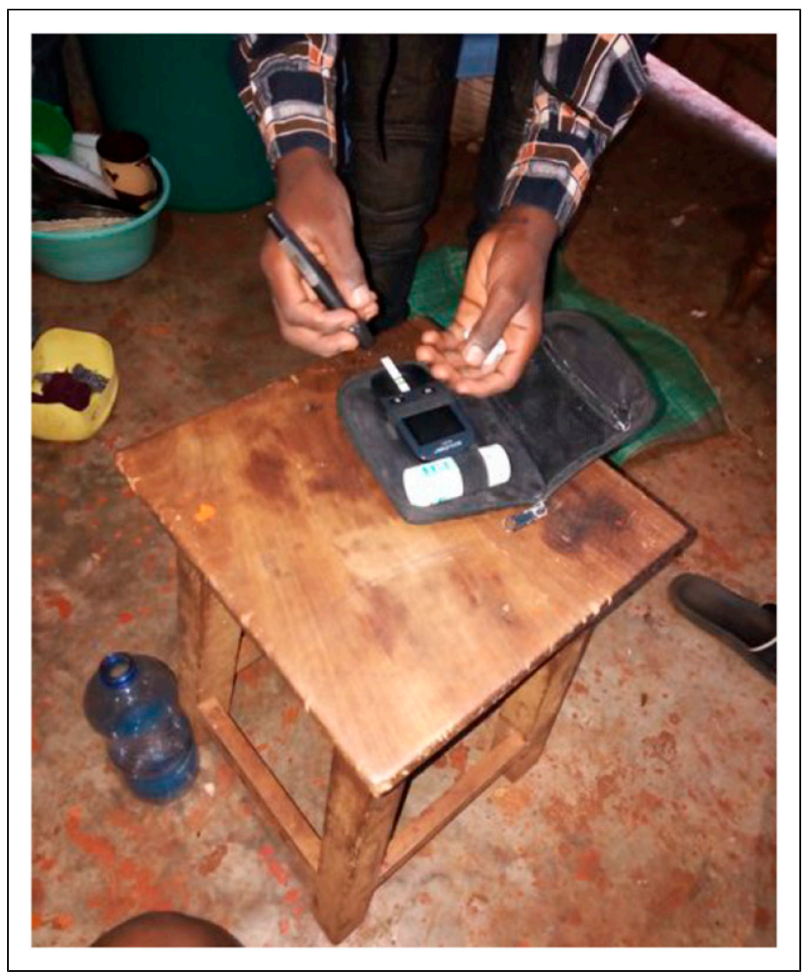

Figure 2. Preparing insulin for injection.

injecting insulin. Many of the photos showed children preparing and injecting insulin (like the example shown in Figure 2), and very young children told us that they knew how to inject insulin themselves:

"No it's not (painful) and I know how to do it"

Boy, 5-8 years old

Young children knew how to store, prepare and inject insulin, as well as how to store needles, which are typically reused:

"I used to be assisted but nowadays it's just me, myself and I. I do the injections myself when I'm in school or I'm at home, I manage my diet, I do everything by myself. I grew up and I decided I didn't want anyone to help me with it...for me I decided I wanted to do it by myself because I don't want any sympathy from them"

Boy, 14-17 years old

We also heard from a healthcare worker that sometimes children's independence is a direct result of their parents' lack of engagement in supervising their diabetes management. They suggested that many parents are scared of the injections and some would even deny any responsibility for their child's diabetes management. However, it is 
worth noting that most families interviewed played an active role in their child's care and were also knowledgeable about diabetes management.

Despite the independence gained from learning to inject themselves, children still had a desire to fit in and be more discrete with their management. This points to a need for more advanced options that are easily available in high income countries but difficult to acquire in this setting:

"It was really hard for me to adapt, especially the first few days, because everyone will just be looking at you injecting yourself, but if you have a pen it's something that is very fast and very quick."

Girl, 14-17 years old

One issue highlighted in the photo diary results was the lack of refrigeration available at home for most children enrolled in the CDiC program, and the makeshift ways of storing insulin that have been used instead. Particularly in the Kenyan climate, poor storage of insulin leads to degraded quality. An inexpensive improvised device, using charcoal, was widely recommended by healthcare workers (see Figure 3). However, there was a risk that the device would not be correctly built or used, spoiling the insulin, and it was also reported that children often did not use the recommended device. Children and parents both reported being able to tell when their insulin has spoiled. The lack of refrigeration at home also meant that children

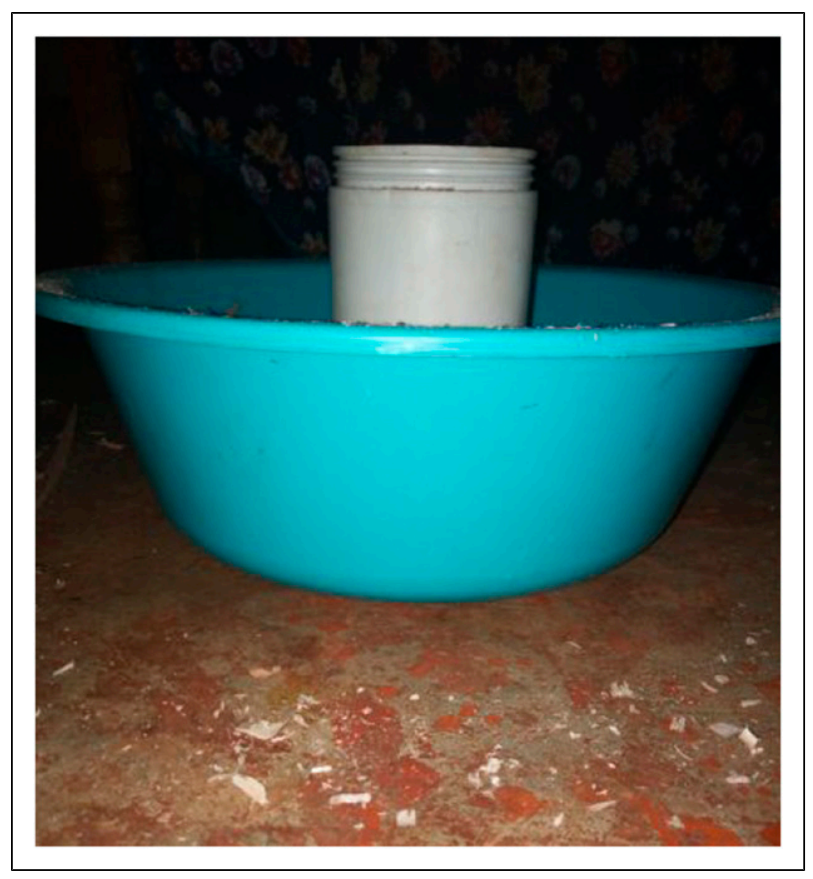

Figure 3. Improvised insulin storage. had to travel to the facility more frequently than they otherwise would. Some parents reported that they found it very difficult to travel with a homemade fridge. As a result, when away from home children may just keep their insulin loose in their bag.

Lack of portable storage facilities also resulted in children altering their insulin dosing schedule, potentially posing a threat to sugar control:

\begin{abstract}
"The one problem I have is with the storage of insulin. The nurse usually stores it for me. However, she normally reports to work later than I should take my insulin. I am usually forced to take my morning dose the previous evening as I do not have proper storage for it."
\end{abstract}

Girl, 14-17 years old

Photo Diary Category 4: Socializing. A final area captured in many of the photos is children's social lives. A large proportion of the photos were simply of the children socializing with their friends or siblings, at home, at school, or at shopping malls. This highlights that diabetic children, although they face many challenges, are able to live "normal" lives like any other child or adolescent.

Amongst the 12 children who were able to provide an approximate estimate, the mean number of years since their diagnosis was 5.25. The remaining three children reported that they were diagnosed too young to remember. Although the period shortly after diagnosis can be marked by resentment and a lack of understanding, over time, it was reported that children developed a good understanding of their condition and management. Many of them, after the initial hurdles, were able to fully accept their condition and develop a strict and independent routine:

"When I wake up in the morning I usually test my sugars and then I inject insulin, and then I usually wait for 30 minutes before I take breakfast. After that I wait until around 10 a.m ... I also do that during lunchtime."

Boy, age unknown

After establishing independence, some children then went ahead to participate in regular activities including participating in sports such as rugby and taking up leadership positions in their schools.

\section{Discussion}

Through this study, we have highlighted some of the challenges faced by children living with T1DM. The impact of T1DM on family life has been extensively documented across different contexts (see Fornasini et al., 2020 for a review). A recent study found that mothers in 
the United Arab Emirates initially reacted with shock and disbelief, before transitioning to near-normal family functioning (Rossiter et al., 2019). However, in a study in Wales, Lowes et al. (2005) outline how a T1DM diagnosis represents a psychosocial transition for parents, one that may initially be met with a resistance to change. The authors suggest that, despite parents adapting to the needs of their child in the first year following diagnosis, they may never fully accept that diagnosis. Similarly, in our study, we also found an increased level of acceptance following diagnosis, alongside evidence that some caregivers never fully come to terms with the diagnosis, "wondering why do I have to go through this." Additionally, a study in Scotland suggests that parents found information overload following diagnosis distressing (Rankin et al., 2016). These issues can only be exacerbated in the context of the financial and other barriers to care in Kenya outlined above. Caregiver support clearly plays a crucial role in overcoming psychosocial challenges (Koller et al., 2015). It is therefore important to provide appropriate psychosocial support for parents and children, in addition to accurate information about diabetes care. A further example of psychosocial support is the residential camps held for children with diabetes and their families in Kenya, where children can learn from and socialize with a large number of peers with T1DM. Increasing feelings of "normalcy" amongst children with T1DM in this way may lead to better integration of diabetes management within daily routines (Commissariat et al., 2016).

In Kenya, awareness of diabetes, and NCDs more generally, is low compared to awareness of communicable diseases such as malaria and HIV. This is particularly true of diabetes amongst children, which still has very low incidence compared to other diseases. The lack of awareness and accurate information highlighted under Theme 1 is one of many factors that mean an estimated $59.7 \%$ of people with diabetes (Type 1 and Type 2) remain undiagnosed in sub-Saharan Africa, compared to 37.8\% in North America and Caribbean, and 40.7\% in Europe (Saeedi et al., 2019). Although stigma is also prevalent in high income settings, the prevalence of beliefs in witchcraft and traditional medicine in Kenya present an additional challenge in promoting adequate care, as it leads parents to act in secrecy. Comparable beliefs may exist in a wide range of other settings, such as the prevalent beliefs in a spiritual "evil eye" causing diabetes previously reported in Tajikistan (Haugvik et al., 2017). Additionally, whereas more advanced technology is commonplace in high income settings, with the uptake of insulin pumps exceeding $60 \%$ in the US (Miller et al., 2015), many children in Kenya struggle to afford the basics of needles and insulin. Though less intrusive technology could improve children's quality of life, and some participants reported that they would like such equipment, it is clear that the basic equipment needs must be met before this can be considered. Widespread issues in insulin access and storage remain and addressing these barriers to basic care must be a more immediate priority than introducing more advanced technology.

The provision of basic equipment is essential for children and adolescents to feel in control of their lives, and for them to be empowered to manage their diabetes. A key message of our results is that diabetes is a "normal" disease and can be managed if only the child is supplied with essential commodities. Yet, children with T1DM have a wide-ranging number of needs, including the need for social support and acceptance. Relatively little attention has been paid in the literature to the issue of schooling for children with T1DM in LMICs, despite the clear importance for children's current and future wellbeing. Poor glycemic control is associated with worse schooling outcomes (see e.g., McCarthy et al., 2003). Beyond glycemic control, the wider impact of living with T1DM on school attendance and outcomes is less clear. Although no relevant data were identified in Kenya, one study in Rwanda found that diabetes affected school attendance for $40.5 \%$ of a Life for a Child cohort, though the reasons for this were not explored (Marshall et al., 2013). However, near-normal school attendance has been identified as a reasonable goal for children with T1DM (e.g., Glaab et al., 2005). This goal should be more explicitly considered as a treatment outcome.

The results outlined above suggest several reasons why school attendance may be affected in settings such as East Africa. Children may face the challenges of uncooperative teachers, a lack of understanding amongst their peers, difficulty maintaining their diet and difficulty storing and administering insulin. Given that children spend so much of their time in school, especially those at boarding schools, it is crucial that their teachers have at least a basic awareness of their needs. Education sessions for teachers to facilitate their participation in children's diabetes care would be beneficial, and should include information on key topics such as insulin administration, exercise and nutrition. Establishing direct links between clinics and schools to enable monitoring would allow ongoing assessment of the knowledge of teachers and their skills. This training could also be extended to classmates. A study in the US found that training teachers and classmates was beneficial for disease control and quality-of-life (Wagner et al., 2006). Although disclosure to friends is associated with successful diabetes care (Wysocki \& Greco, 2006), many children felt the need to hide their diabetes at school. This issue is also prevalent in high income settings, with one study in Spain finding that $25 \%$ of children and adolescents with T1DM concealed their illness at school (Amillategui et al., 2007). 
To facilitate self-care for chronic diseases, Beran (2015) highlighted the need for a comprehensive examination of the whole range of health needs individuals face, rather than focusing solely on specific needs, such as healthcare needs, in isolation. For example, children need to be adequately assessed for comorbidities whose management may have a negative impact on diabetes management. For example, families of children with some comorbidities, such as autism, may benefit greatly from the support of a dietician in balancing out disease management while also providing a balanced diet from locally available foods. However, changing attitudes in communities by raising awareness and challenging misconceptions may be challenging. The stigma experienced by those with T1DM may hinder attempts to increase awareness and other patient advocacy efforts. More opportunities for peer-to-peer learning and hearing the stories of adults who have lived with diabetes can give children hope and help to ease their fears. Many of them do not know anyone else with diabetes. Often both parents and children are anxious over schooling and career prospects. This can make the transition from pediatric to adult care challenging. A recent study in Canada found that many youths felt that they did not receive adequate preparation for this transition, and identified peer support as one potential strategy to improve the transition (Butalia et al., 2020). Seeing older people with diabetes who have gone on to successful careers and have successfully managed their illness and maintained their health conveys a very powerful message to children and their parents. Empowering diabetic children and their carers to be able to defend their interests will also help to enable stronger patient advocacy, including working toward affordable insulin at the national level.

\section{Limitations}

This study has several limitations. Although the children participating in this study faced many challenges, they were regular attendees at diabetes clinics. It was not possible to include children with diabetes who are unable to access care, and who likely have more complex needs than our participants. Additionally, it would be interesting to include children's peers and teachers in future studies in order to address the issue of stigma and social support in schools. Although we originally intended to use photovoice methodology, photo diary data was unfortunately not discussed with the children in a follow-up session due to logistical constraints. Photovoice methodology would have enriched our analysis. Finally, it was not possible to publish many of the photos generated during the photo diary activity for data protection reasons, as most of the photos included faces enabling identification of participants.

\section{Conclusion}

Children with T1DM in Kenya face a variety of barriers to care, including lack of resources, stigma, and a lack of support from family or peers. These barriers must be addressed to enable them to lead a "normal" and fulfilling life. Although there remain widespread issues in insulin access and storage, the four overarching themes identified (i.e., knowledge and awareness, economic exclusion, the importance of social support, and striving for normality) all have a psychosocial component. Caregiver support clearly plays a crucial role in overcoming psychosocial challenges. To our knowledge, this was the first study to use photo diaries to provide insight into the experiences of children with diabetes in Kenya. The study demonstrated that photo diary methods can be used successfully in lowincome settings, where children are not necessarily familiar with smartphone technology. To improve the care and the lives of children with diabetes, stakeholders must take note of their experiences and recognize their multidimensional needs.

\section{Declaration of Conflicting Interests}

The author(s) declared no potential conflicts of interest with respect to the research, authorship, and/or publication of this article.

\section{Funding}

The author(s) disclosed receipt of the following financial support for the research, authorship, and/or publication of this article: This study was supported by Novo Nordisk.

\section{ORCID iD}

Tom Palmer (D) https://orcid.org/0000-0002-9526-0045

\section{References}

Abdoli, S., Abazari, P., \& Mardanian, L. (2013). Exploring diabetes type 1-related stigma. Iranian Journal of Nursing and Midwifery Research, 18(1), 65-70. https://www.ncbi. nlm.nih.gov/pmc/articles/PMC3748558/.

Allen, L. (2009). 'Caught in the act': Ethics committee review and researching the sexual culture of schools. Qualitative Research, 9(4), 395-410. https://doi.org/10.1177/ 1468794109337866

Amillategui, B., Calle, J. R., Alvarez, M. A., Cardiel, M. A., \& Barrio, R. (2007). Identifying the special needs of children with Type 1 diabetes in the school setting. An overview of parents' perceptions. Diabetic Medicine: A Journal of the British Diabetic Association, 24(10), 1073-1079. https:// doi.org/10.1111/j.1464-5491.2007.02250.x

Aono, S., Matsuura, N., Amemiya, S., Igarashi, Y., Uchigata, Y., Urakami, T., Kida, K., Sasaki, N., Miki, Y., \& Miyamoto, S. (2000). Marriage rate and number of children among young 
adults with insulin-dependent diabetes mellitus in Japan. Diabetes Research and Clinical Practice, 49(2), 135-141. https://doi.org/10.1016/S0168-8227(00)00137-6

Beran, D. (2015). Needs and needs assessments: A gap in the literature for chronic diseases. Sage Open, 5(2), 2158244015580375. https://doi.org/10.1177/2158244015580375

Braun, V., \& Clarke, V. (2006). Using thematic analysis in psychology. Qualitative Research in Psychology, 3(2), 77-101. https://doi.org/10.1191/1478088706qp063oa

Brazeau, A.-S., Nakhla, M., Wright, M., Henderson, M., Panagiotopoulos, C., Pacaud, D., Kearns, P., Rahme, E., Costa, D. D., \& Dasgupta, K. (2018). Stigma and its association with glycemic control and hypoglycemia in adolescents and young adults with type 1 diabetes: Crosssectional study. Journal of Medical Internet Research, 20(4), e151. https://doi.org/10.2196/jmir.9432

Butalia, S., McGuire, K. A., Dyjur, D., Mercer, J., \& Pacaud, D. (2020). Youth with diabetes and their parents' perspectives on transition care from pediatric to adult diabetes care services: A qualitative study. Health Science Reports, 3(3), e181. https://doi.org/10.1002/hsr2.181

Capistrant, B. D., Friedemann-Sánchez, G., \& Pendsey, S. (2019). Diabetes stigma, parent depressive symptoms and Type-1 diabetes glycemic control in India. Social Work in Health Care, 58(10), 919-935. https://doi.org/10.1080/ 00981389.2019 .1679321

Commissariat, P. V., Kenowitz, J. R., Trast, J., Heptulla, R. A., \& Gonzalez, J. S. (2016). Developing a personal and social identity with type 1 diabetes during adolescence: A hypothesis generative study. Qualitative Health Research, 26(5), 672-684. https://doi.org/10.1177/1049732316628835

Dashiff, C., Hardeman, T., \& McLain, R. (2008). Parent-adolescent communication and diabetes: An integrative review. Journal of Advanced Nursing, 62(2), 140-162. https://doi. org/10.1111/j.1365-2648.2007.04549.x

Diabetes Control and Complications Trial Research Group. (1993). The effect of intensive treatment of diabetes on the development and progression of long-term complications in insulin-dependent diabetes mellitus. New England Journal of Medicine, 329(14), 977-986. https://doi.org/10.1056/ NEJM199309303291401

Fornasini, S., Miele, F., \& Piras, E. M. (2020). The consequences of type 1 diabetes onset on family life. An integrative review. Journal of Child and Family Studies, 29(5), 1467-1483. https://doi.org/10.1007/s10826-019-01544-z

Glaab, L. A., Brown, R., \& Daneman, D. (2005). School attendance in children with Type 1 diabetes. Diabetic Medicine, 22(4), 421-426. https://doi.org/10.1111/j.14645491.2005.01441.x

Gredig, D., \& Bartelsen-Raemy, A. (2017). Diabetes-related stigma affects the quality of life of people living with diabetes mellitus in Switzerland: Implications for healthcare providers. Health \& Social Care in the Community, 25(5), 1620-1633. https://doi.org/10.1111/hsc.12376
Hapunda, G., Abubakar, A., van de Vijver, F., \& Pouwer, F. (2015). Living with type 1 diabetes is challenging for Zambian adolescents: Qualitative data on stress, coping with stress and quality of care and life. BMC Endocrine Disorders, 15(1), 20. https://doi.org/10.1186/s12902-015-0013-6

Haugvik, S., Beran, D., Klassen, P., Hussain, A., \& Haaland, A. (2017). "My heart burns" - A qualitative study of perceptions and experiences of type 1 diabetes among children and youths in Tajikistan. Chronic Illness, 13(2), 128-139. https://doi.org/10.1177/1742395316668566

Huus, K. (2007). Adolescents' experience of living with diabetes. Nursing Children and Young People, 19(3), 29-31. https://doi.org/10.7748/paed.19.3.29.s24

Jaacks, L. M., Liu, W., Ji, L., \& Mayer-Davis, E. J. (2015). Type 1 diabetes stigma in China: A call to end the devaluation of individuals living with a manageable chronic disease. Diabetes Research and Clinical Practice, 107(2), 306-307. https://doi.org/10.1016/j.diabres.2014.12.002

Kerr, C., Nixon, A., \& Wild, D. (2010). Assessing and demonstrating data saturation in qualitative inquiry supporting patient-reported outcomes research. Expert Review of Pharmacoeconomics \& Outcomes Research, 10(3), 269-281. https://doi.org/10.1586/erp.10.30

Kleine, D., Pearson, G., \& Poveda, S. (2016). Participatory methods: Engaging children's voices and experiences in research [Monograph]. The London School of Economics and Political Science. http://eprints.lse.ac.uk/71261/

Koller, D., Khan, N., \& Barrett, S. (2015). Pediatric perspectives on diabetes self-care: A process of achieving acceptance. Qualitative Health Research, 25(2), 264-275. https://doi. org/10.1177/1049732314551057

Kratzer, J. (2012). Structural barriers to coping with type 1 diabetes mellitus in Ghana: Experiences of diabetic youth and their families. Ghana Medical Journal, 46(2 Suppl), 39-45. https://doi.org/10.4314/GMJ.V46I2

Liu, N. F., Brown, A. S., Folias, A. E., Younge, M. F., Guzman, S. J., Close, K. L., \& Wood, R. (2017). Stigma in people with type 1 or type 2 diabetes. Clinical Diabetes, 35(1), 27-34. https://doi.org/10.2337/cd16-0020

Lowes, L., Gregory, J. W., \& Lyne, P. (2005). Newly diagnosed childhood diabetes: A psychosocial transition for parents? Journal of Advanced Nursing, 50(3), 253-261. https://doi. org/10.1111/j.1365-2648.2005.03388.x

Marshall, M., Carter, B., Rose, K., \& Brotherton, A. (2009). Living with type 1 diabetes: Perceptions of children and their parents. Journal of Clinical Nursing, 18(12), 1703-1710. https://doi.org/10.1111/j.1365-2702.2008.02737.x

Marshall, S., Edidin, D., Sharma, V., Ogle, G., Arena, V. C., \& Orchard, T. (2013). Current clinical status, glucose control, and complication rates of children and youth with type 1 diabetes in Rwanda. Pediatric Diabetes, 14(3), 217-226. https://doi.org/10.1111/pedi.12007

McCarthy, A. M., Lindgren, S., Mengeling, M. A., Tsalikian, E., \& Engvall, J. (2003). Factors associated with academic 
achievement in children with type 1 diabetes. Diabetes Care, 26(1), 112-117. https://doi.org/10.2337/diacare.26.1.112

Miller, S. (1999). Hearing from children who have diabetes. Journal of Child Health Care, 3(1), 5-12. https://doi.org/ 10.1177/136749359900300101

Miller, K., Foster, N. C., Beck, R. W., Bergenstal, R. M., DuBose, S. N., DiMeglio, L. A., Maahs, D. M., \& Tamborlane, W. V., T1D Exchange Clinic Network. (2015). Current state of type 1 diabetes treatment in the U.S.: Updated data from the T1D Exchange clinic registry. Diabetes Care, 38(6), 971-978. https://doi.org/10.2337/dc15-0078

Ministry of Health. (2014). Kenya Health Policy 2014-2030. http://publications.universalhealth2030.org/uploads/kenya health policy 2014 to 2030.pdf

Mizen, P. (2005). A little 'light work'? Children's images of their labour. Visual Studies, 20(2), 124-139. https://doi.org/10. 1080/14725860500244001

Morse, J. M. (2015). Critical analysis of strategies for determining rigor in qualitative inquiry. Qualitative Health Research, 25(9), 1212-1222. https://doi.org/10.1177/1049732315588501

Ngwiri, T., Were, F., Predieri, B., Ngugi, P., \& Iughetti, L. (2015). Glycemic control in Kenyan children and adolescents with type 1 diabetes mellitus. International Journal of Endocrinology, 2015(3), 1-7. https://doi.org/10.1155/2015/761759

Ogle, G. D., Kim, H., Middlehurst, A. C., Silink, M., \& Jenkins, A. J. (2016). Financial costs for families of children with Type 1 diabetes in lower-income countries. Diabetic Medicine, 33(6), 820-826. https://doi.org/10.1111/dme.12997

Palmer, T., Jennings, H. M., Shannon, G., Salustri, F., Grewal, G., Chelagat, W., Sarker, M., Haghparast-Bidgoli, H., Pelletier, N., \& Skordis, J. (2021). Improving access to diabetes care for children: An evaluation of the changing diabetes in children project in Kenya and Bangladesh. (Manuscript under review) [Unpublished].

Punch, S. (2002). Research with children: The same or different from research with adults? Childhood, 9(3), 321-341. https://doi.org/10.1177/0907568202009003005

Rankin, D., Harden, J., Barnard, K. D., Stephen, J., Kumar, S., \& Lawton, J. (2018). Pre-adolescent children's experiences of receiving diabetes-related support from friends and peers: A qualitative study. Health Expectations, 21(5), 870-877. https://doi.org/10.1111/hex.12802

Rankin, D., Harden, J., Waugh, N., Noyes, K., Barnard, K. D., \& Lawton, J. (2016). Parents' information and support needs when their child is diagnosed with type 1 diabetes: A qualitative study. Health Expectations, 19(3), 580-591. https://doi.org/10.1111/hex.12244

Rossiter, R. C., Cooper, J. L., Marjei, S. I., \& Brownie, S. (2019) Case-based insights: Arab Muslim mothers' experiences of managing a child newly diagnosed with type 1 diabetes mellitus. SAGE Open Nursing, 5, 2377960819870979. https://doi.org/10.1177/2377960819870979

Saeedi, P., Petersohn, I., Salpea, P., Malanda, B., Karuranga, S., Unwin, N., Colagiuri, S., Guariguata, L., Motala, A. A., \& Ogurtsova, K. (2019). Global and regional diabetes prevalence estimates for 2019 and projections for 2030 and 2045: Results from the International diabetes federation diabetes atlas. Diabetes Research and Clinical Practice, 157, 107843. https://doi.org/10.1016/j.diabres.2019.107843

Souris, K. J., Caballero Gonzalesdel, M.C., Barrington, C., Klatman, E. L., Anderson, B. J., Duarte, E., Middlehurst, A. C., Nostas, M. C., \& Ogle, G. D. (2019). 'La Vida Normal': Young people adapting to Type 1 diabetes in Bolivia. Chronic Illness, 17(3), 1742395319843172. https://doi.org/10.1177/1742395319843172

Sparapani, V. d. C., Jacob, E., \& Nascimento, L. C. (2015). What is it like to be a child with type 1 diabetes mellitus? $\mathrm{Pe}$ diatric Nursing, 41(1), 17-22. https://pubmed.ncbi.nlm.nih. gov/26281271/.

Wagner, J., Heapy, A., James, A., \& Abbott, G. (2006). Brief report: Glycemic control, quality of life, and school experiences among students with diabetes. Journal of Pediatric Psychology, 31(8), 764-769. https://doi.org/10.1093/ jpepsy/jsj082

Walker, A., Schatz, D., Johnson, C., Silverstein, J., Lyles, S., \& Rohrs, H. (2016). Type 1 diabetes through two lenses: Comparing adolescent and parental perspectives with photovoice. International Journal of Pediatric Endocrinology, 2016(1), 2. https://doi.org/10.1186/s13633-0160020-Z

Wysocki, T., \& Greco, P. (2006). Social support and diabetes management in childhood and adolescence: Influence of parents and friends. Current Diabetes Reports, 6(2), 117-122. https://doi.org/10.1007/s11892-006-0022-y

Wysocki, T., Nansel, T. R., Holmbeck, G. N., Chen, R., Laffel, L., Anderson, B. J., \& Weissberg-Benchell, J., Steering Committee of the Family Management of Childhood Diabetes Study. (2009). Collaborative involvement of primary and secondary caregivers: Associations with youths' diabetes outcomes. Journal of Pediatric Psychology, 34(8), 869-881. https://doi.org/10.1093/jpepsy/jsn136

Yi-Frazier, J. P., Cochrane, K., Mitrovich, C., Pascual, M., Buscaino, E., Eaton, L., Panlasigui, N., Clopp, B., \& Malik, F. (2015). Using Instagram as a modified application of photovoice for storytelling and sharing in adolescents with type 1 diabetes. Qualitative Health Research, 25(10), 1372-1382. https://doi.org/10.1177/1049732315583282

Young, L., \& Barrett, H. (2001). Adapting visual methods: Action research with Kampala street children. Area, 33(2), 141-152. https://doi.org/10.1111/1475-4762.00017 